\title{
Necati Cumalı Eserlerinde Kadın Karakterlerin İletişim Dili: Dila Hanım Örneği
}

Doç. Dr. Emine KILIÇASLAN

Aydın Adnan Menderes Üniversitesi

Aydın Meslek Yüksekokulu

emine.kilicaslan@adu.edu.tr

ORCID: 0000-0002-4226-9409

\begin{abstract}
Öz
Necati Cumalı, tüm hayatını oldukça üretken bir şekilde yazma eylemine adamış önemli bir Cumhuriyet yazarıdır. Cumalı'nın, öyküleri romanları ve şiirlerinin yanı sıra yazdığı yirmi dokuz oyunu bulunmaktadır. Bu eserlerden bazıları tiyatro olarak sahnelenmiştir. Bazı romanları da Yeşilçam filmlerine konu olmuştur. Necati Cumalı'nın, eserlerinin işleyişine bakıldığında, kırsal kesim ilişkileri ve kasaba hayatında insan ilişkileri dikkat çekmektedir. Bu ilişkiler oldukça sıradan insanların, aile yaşamı, komşuluk ilişkileri olarak vurgulanmaktadır. Bu ilişkilerin iletileri, cinsellik, aldatma, kavga, dedikodu ve toprak kavgası gibi örüntüler içinde kadının yerini genç Cumhuriyetin geleneksel kültürü içinde eleştirel tarzda göstermektedir. Cumalı eserlerinde kadın karakterlerin rollerini ve statülerini geleneksel kültürün içinde işlemiştir. Sıradan kadını anlatırken kadının kültür içinde ezilen ve yok edilen duygularını vermektedir. Bu yok edilişe karşı boyun eğen kadın figürünün yanında duygularına ve arzularına teslim olan kadın figürlerine de eserlerinde yer vermiştir. Bu kadın figürlerinden en farklı olanı, Dila Hanım eserinde yer alan kadın modelidir. Çünkü Dila Hanım, Cumall'nın eserlerinde işlediği diğer sıradan kadın figürlerinin dışına çıkmışıı. Dila Hanım, ata binen, silah kullanan, kinini güden ve kanını yerde bırakmayan bir kadın figürü olarak okuyucunun karşııına çıkmaktadır. Fakat, güçlü bir kadın karakter olan Dila Hanım bile geleneklere karşı çıkamamışır. Aşkı yerine intihar etmeyi tercih etmiştir. Bu nedenle bu çalışmada Necati Cumalı öykülerinden Dila Hanım incelenmiştir.
\end{abstract}

Anahtar Kelimeler: necati cumalı, kadın, dila hanım karakteri.

Kılıçaslan, E. (2021). Necati Cumalı Eserlerinde Kadın Karakterlerin İletişim Dili: Dila Hanım Örneği. ARTS: Artuklu Sanat ve Beşeri Bilimler Dergisi, Necati Cumalı Özel Sayısı, ss. 136-148. 


\title{
arts
}

Research Article

\section{Communication Language of Female Characters in Necati Cumalı Works: Sample of Dila Hanım}

\begin{abstract}
Necati Cumalı is an important Republic writer who has devoted his entire life to writing in a very productive way. Cumalı has twenty-nine plays written in addition to his stories, novels and poems. Some of these works have been staged as theater. Some of his novels have been the subject of Yeşilçam movies. When looking at Necati Cumalı's processing of his works, rural relations and human relations in town life draw attention. These relationships are emphasized as family life and neighborhood relationships of quite ordinary people. The messages of these relations critically show the place of women in the traditional culture of the young Republic in patterns such as sexuality, deception, quarrel, gossip and land fight. In his works, Cumali, has covered the roles and status of female characters in traditional culture. While describing the ordinary woman, he gives the feelings of the woman being oppressed and destroyed in the culture. In addition to the female figure who succumbed to this destruction, he also included female figures surrendering to her feelings and desires. The most interesting of these female figures is the female model in Dila Hanım's work. Dila Hanım has gone beyond ordinary female figures. Dila Hanım appears before the reader as a female figure riding a horse, using a gun, holding her grudge and blood on the ground. Dila Hanım, who is a strong character, could not oppose the tradition. She preferred to commit suicide instead of love. For this reason, Dila Hanım from the stories of Cumalı was examined in this study.
\end{abstract}

Keywords: necati cumalı, female, dila hanım character. 


\section{arts}

\section{GíRiş}

Genç Türkiye Cumhuriyeti'nin aydınlanma ve yükselme döneminin en önemli yazarlarından olan Necati Cumalı, tüm hayatını oldukça üretken bir şekilde yazma eylemine adamıştır. Necati Cumalı, edebiyatın pek çok alanında, öykü, roman, şiir, oyun, deneme türü eserler vermiştir. Genç ve yükselen Türkiye Cumhuriyeti'nin ○ yıllardaki geleneksel ilişkileri, Necati Cumalı eserlerinde görülmektedir. Cumalı, eserlerinde, kırsal kesim ilişkileri ve kasaba hayatında insan ilişkilerini eleştirel bir yaklaşımla anlatarak insanların ve özellikle kadınların acılarına, üzüntülerine ve ezilmişliklerine dikkat çekmektedir. Bu ilişkilerin anlatımında oldukça sade bir dil kullanımaktadır. Bu sade dil aslında eserlerin gücünün göstergesidir. Cumalı, eserlerinde, sıradan insanların, aile yaşamı, komşuluk ilişkileri ve çevresi ile kurduğu iletişimi sade bir Türkçe ile vurgulamaktadır. Bu ilişkilerin iletileri, cinsellik, aldatma, kavga, dedikodu ve toprak kavgası gibi örüntüler içinde kadının yerini de göstermektedir. Bu bağlamda, Cumalı'nın, öykü, roman ve diğer eserlerinde kadını tanımlayan iletilerinde kadının geleneksel kültür içindeki rolü ve statüsü görülmektedir. Necati Cumalı'nın, eserlerinde yer alan sıradan kadın, eş, anne ve çocuk statülerinde, kıskançlık, aşk, cinsellik, gibi insani duygular ile hayattaki rollerini sürdürmektedir.

Cumhuriyet tarihinin en önemli yazarlarından biri olan Cumalı, Türk hikâyeciliğinin gelişme döneminde gerçekçilik çizgisinde anlatımlarla toplumsal aktarımda bulunmuş önemli bir toplumsal dönüşüm yazarıdır. Necati Cumall, gerek Cumhuriyet öncesinden gelen gerekse sonrasında, hiçbir edebi akımın içine girmemiştir. Cumalı, kendi özgün anlatımı ile serbest hikâyeler, romanlar, şirler ve tiyatro oyunları yazmıştır. Bu eserlerde Necati Cumalı'nın en önemli odak noktası "insan" olmuştur. İnsanı anlatırken Necati Cumalı toplumsal sorunlara değinmiştir. Bu bağlamda içinde yaşadığı topluma değer veren yazar bireyden hareketle toplumsal sorunlara vurgu yapmışıı. Bu sorunlara dikkat çekerken, aşk, sevgi, dostluk ve savaş, barış gibi kavramları eserlerinde işlemiştir. Bu işleme tarzında oldukça sade bir dil kullanarak geniş halk kitlelerine ulaşma amacı içinde olmuştur. Eserlerinde güçlü bir Türkçe kullanımı görülen Cumalı, bu tarzıla genç Cumhuriyetin yetişen yeni kuşaklarına gerçekçi eserleriyle ulaşmışır. 
Eserlerinde Türkçeyi oldukça yalın bir biçimde kullanmaya özen gösteren Cumalı, temaları somut düzlemde kurgulamışıı. Yazarın akıcı bir üslubu bulunmaktadır. Bu akıcı üslup eserin konusunun dinamik bir işleyişe sahip olmasından kaynaklanmaktadır. Necati Cumalı'nın, eserlerinde kullandığı sade ve etkileyici dil onun anlaşılır olmasını sağlamıştır. Bu bağlamda Cumalı, eserlerinde anlaşılır olmaktan ve öz kültür ile Türkçe'nin yalın kullanımından ödün vermeden eserlerini vermiştir. Ayrıca, eserlerinde Anadolu insanının yaşayış biçimini, duygulanışını anlatırken ulusal edebiyatın oluşmasında öncü yazarlardan olmuştur. Buradan hareketle Cumalı, eserlerinde yerel değerlere oldukça önem vermiştir. Edebiyatın tüm alanlarında eserleri bulunan Necati Cumalı, iyi bir gözlemci olmuştur. Bu bağlamda eserleri gerçek hayatın betimlemelerine sahip ve yerel unsurlar taşımaktadır. Yazarın, çoğu eserinde kadın-erkek ilişkileri cinsellik teması ile birlikte ele alınmıştır.

Cumhuriyet tarihinin önemli yazarlarından olan Necati Cumalı, hayatının 60 yılını, şiir, roman, öykü, deneme, oyun gibi Türk Cumhuriyet dönemi edebiyatına adamıştır. Türk Cumhuriyet tarihinin en önemli yazarlarından biri olarak yazarlık hayatını; biri uyarlama olmak üzere yirmi dört oyun, on dört şiir kitabı, dokuz hikaye kitabı, altı roman, altı deneme, bir senaryo, bir hatıra kitabı, beş çeviri ve iki inceleme olmak üzere toplam altmış sekiz eser ile taçlandırmıştır.

\section{NECATI CUMALI HAYATI VE ESERLERI}

Uzun adı, Ahmet Necati Cumalı, 13 Ocak 1921'de Florino, Batı Makedonya bölgesi, Yunanistan' da doğmuştur. Kendi ağzından Cumalı, "Mustafa-Fitnat Cumalı çiftinin ilk çocuğudur. 13 Ocak 1921'de "Psoderi dağının eteklerinden inen derin bir koyağın ağzında" kurulan Florino'da, "Rum mahallesinin sonunda Müslüman mahallesinin girişinde... Kalın biçilmiş ağaçtan aşı boyalı çift kanatı kapısı ile... Bitişiğindeki çift kanatı Rum evi yanında, güzel duracak kadar uyumlu, gösterişli, doğmuştur" (Demir, 1995) kendi dilinden anlatmaktadır.

Necati Cumalı'nın hayatında ve eserlerinde babasından daha çok büyükbabası önemli yer tutmuştur. Bu nedenle "Babam" adlı hikâyesinde büyükbabası İbrahim Efendiyi anlatmaktadır. "Babam" hikayesinde büyükbabasını betimleme iletileri arasında "dindar", "mütevazı", memleketini seven", "mücadeleci" 


\section{arts}

ve "otoriter" tasvirleri kullanılmıştır. Cumalı büyük babasını anlatırken büyük babasının dindar bir adam oluşunu Kur'an okurken duyduğu mutlulukla birleştirmektedir. Bu durumu büyükbabasının dükkânı, evi, eşi bağı ve tarlası ile Kur'an arasındaki bağlantıyı anlatarak açıklamaktadır. Cumalı, "büyükbabam 1927' de öldü. Ben altı yaşındayken yediyi sürerken... Büyükbabam ilginç adamdı benim. Dindar. Bakın nasıl dindar? Kendisi hattat, el yazması Kur'an'ları var... Buna karşılık gizli İttihat ve Terakki Planlı kurucusu ve başkanı" (Taş, 2001, s. 325) anlatımı ile kendi köklerine ilişkin çok önemli bilgileri aktarmaktadır.

Bu bağlamda Necati Cumalı'nın hayatında dedesi İbrahim Efendi'nin çok önemli bir yeri olduğu anlatımlarında görülmektedir. Cumalı'nın dedesi İbrahim Efendi hayatı zorluklarla geçmiş bir kişidir. Dedesi ỉbrahim Efendi, erkek kardeşi ile arasının bozulması nedeniyle 30'lu yaşlarda Anadolu'ya göç eder ve Balıkesir, Havran' a yerleşir. Burada ticaret ile uğraşarak hayatını devam ettirir. Fakat memleketi Florina'yı çok sevdiği için tekrar oraya geri döner ve Florina' da ikinci kez evlenir.

1921 yllında, Florina'da doğan, Necati Cumalı, mübadele sonucunda ailesiyle Türkiye'ye göç ederek İzmir'in, Urla ilçesine yerleşmiştir. Eserlerinin çoğunda İmir ve çevresini anlatmıştır. Fakat Viran Dağlar ve Dila Hanım (Cumalı, 1995) gibi eserlerinde doğduğu yer olan Florina ve Cuma köyünü anlatmaktadır. Ayrıca, Necati Cumalı, " Kaylar Rehberim" isimli hikâyesinde soyadının nereden geldiğini anlatmıştır. Bu hikayede soyadının köklerinin Makedonya'da, annesinin yaşadığı kasabanın ismi olan Kaylar'ın şimdi ismi Ptolemais' den geldiğinden bahsetmiştir. "Cuma" sözcüğünün ise Ptolemais'in güneyinde kalan kasabanın adı olduğunu vurgular.

Cumalı'nın hayatını en fazla etkileyen olay olan "mübadele" süreci ve bu süreçte ailesinin bu olaydan dolayıyaşadığı üzüntüleri anlatmıştır. Lozan Antlaşmasının imzalanıp Anadolu'da yaşayan Rumlarla, Yunanistan ve Makedonya'da yaşayan Türklerin mübadelesi Necati Cumalı'nın ailesini de derinden etkilemiştir. Dedesi İbrahim Efendi, 93 yaşında tekrar Florina' dan ayrılınca felç geçirmiştir. Aile İzmir'in Urla ilçesine yerleşmiştir. Dedesi İbrahim Efendi üç yıl sonra ölmüştür. 1924'te gerçekleşen bu göç üç yaşındaki Necati Cumalı'yı derinden etkilemiştir. Bu durumu ilerleyen hayatında Cumalı, "bir göç yaşadım, dil değiştirdim" (Cumalı, 1995, s. 50) 
olarak ifade etmiştir.

Çocukluk ve ilk gençlik yılları İmir'in Urla ilçesinde geçen Necati Cumalı, Urla'nın büyüleyici güzelliğinin yanında varlıklı bir aile iken 1929 ekonomik krizi nedeniyle yaşadıkları yoksulluğu da anlatmaktadır. İlkokulu Urla'da, Ortaokulu İzmir' de okumuştur. O yıllarda Necip Fazıl şiirlerinden sonrasında da Nazım Hikmet'ten etkilenmiştir. Genç Türkiye Cumhuriyeti'nin uluslaşma sürecinde büyüyen Cumall, "Varlık, Yücel, Gündüz, Çığır" gibi dergileri takip etmeye başlar. Orhan Veli, Oktay Rıfat ve Melih Cevdet'in "Garip" anlayışı içinde yayınladıkları ilk şiirleri de takip etmiştir.

1938 yılında İstanbul Hukuk Fakültesine öğrenci olarak kayı† yaptıran Necati Cumalı buradaki öğrenimini yaşadığı aşkın depresyonu nedeniyle tamamlayamaz. Sonrasında kaydını Ankara Hukuk Fakültesine yaptıran Necati Cumalı, buradan mezun olur.

Necati Cumalı'nın, ilk şiiri, 1940 yılında Varlık dergisinde "Netice" ismi ile yayınlanır. Bu süreçte tanıştığı Orhan Veli, Oktay Rıfat, Cahit Sıtkı Tarancı ve Nurullah Ataç' ın kendisi yüreklendirmesinden duyduğu memnuniyeti anlatır. Cumalı, Jack London, Maksim Gorki, Balzac ve Dostoyevski gibi klasikleşmiş sanatçıların eserlerini de okuduğunu belirtmiştir.

Ankara Hukuk Fakültesi'nden mezun olduktan sonra önce yine Ankara'da Toprak Mahsulleri Ofisi'nde sonrasında Milli Eğitim Bakanlığı, Güzel Sanatlar Müdürlüğünde memuriyet yapmıştır. Ankara'da memuriyeti sürecinde, "Nurullah Ataç, Sabahattin Eyüpoğlu, Erol Dora Günay, Ahmet Adnan Saygun, Ahmet Hamdi Tanpınar, Pertev Naili Boratav" gibi Cumhuriyet' in önemli sanatçıları ile arkadaşlık etmiştir.

Necati Cumalı'nın hayatına bakıldığında en dikkat çeken şey çok yönlü bir sanatçı olmasıdır. Bu bağlamda Cumalı'nın şiirleri, tiyatro oyunları, roman, hikâye ve denemeleri Cumhuriyet tarihinin en önemli dönemlerine tanıklık etmektedir. Türk edebiyatına önemli katkılarda bulunan Cumalı, 10 Ocak 2001 tarihinde vefat etmiştir. 


\section{arts}

\section{NECATI CUMALI ESERLERINDE KADIN TEMASI VE ÍLETiLERI}

Necati Cumalı, genç Türkiye Cumhuriyeti'nin gerçekçi bir yazarı olarak eserlerinde kadınları hayatın içinde statü ve rollerini geleneksel kültür içinde anlatmaktadır. Bu bağlamda kadın Cumalı eserlerinde; eş, anne, kardeş, sevgili, âşık vb. rolleri içinde verilirken kültürel örüntü içinde varoluş savaşı ile de anlatılmaktadır. Aşağıda yer alan örnekler Necati Cumalı'nın eserlerinde geçen kadın figürlerinin hangi iletilerle yer aldığını göstermektedir.

Örneğin, Cumalı'nın en önemli eserlerinden olan Susuz Yaz' a bakıldığında, su sorunu ve kardeş kavgası üzerine kurulu bir hikaye dikkat çekmektedir. Su kavgasının arkasında kardeşi hapse düşen ağabeyin kardeşinin karısı ile olan ilişkisi eleştirel bir dille anlatımaktadır. Burada kadına cinsel bir meta bakış açısı dikkat çekmektedir. Ayrıca Anadolu'da sıklıkla yaşanan bu durumun ahlak dışı oluşuna da vurgu yapılmaktadır.

Cumalı'nın Ezik Otlar oyununda ise dikkat çeken şey diğer eserlerinde de sık sık vurgulanmaktadır. Anadolu insanının toprak ile ilişkisi ve geleneklere karşı içgüdülerine yenik düşmesi ağırıklı olarak kadın figürler üzerinden anlatılmıştır. Ezik Otlar oyununda Gülsüm'le Kenan arasındaki aşk, aile, çevre ve gelenekler nedeniyle hüsranla sonuçlanmaktadır. Gülsüm her şeyi göze alıp, geleneklere başkaldırsa da ailesine ve çevresine yenilir. Aynı, Susuz Yaz eserinde olduğu gibi Ezik Otlar eserinde de Anadolu insanının en temel sorunlarından olan toprak sorunu, kadınlara yapılan baskı etrafında işlenmiştir. Geleneksel kültürden kaynaklanan törelerin katıı̆ğı Anadolu insanının namus anlayışı ve kan davası bu hikâyede anlatımıştır.

Nalınlar hikâyesi ise tematik anlamda Ezik Otlar ile benzerlikler gösteren bir oyundur. Birbirini seven iki gencin evlenmelerine karşı çıkılmasının konu edinildiği bir oyun olan Ezik Otlar'da Seher, Nalınlar'da da Gülsüm vardır. Hem Nalınlar hem de Ezik Otlar eserlerinde, sevda çeken genç kızın annesi ve ağabeyi ilişkiye karşı çıkar. Nalınlar'da sevilen erkek Kenan, başka yerlerden geldiği için çevreyle bağdaşamazken, Ezik Otlar' da, Osman aile durumu bakımından yadırganır. Gülsüm ile Seher aynı yazgıyı yaşarlar. Seher geleneklere aykırı davranarak sevdiğine kaçar fakat Gülsüm, belki de ailesine olan bağllığından bunu yapmak. Seher kaçarak 
mutluluğa ermek ister, Gülsüm mutsuzluğun kucağına düşer. Çevrenin ve ailenin geleneği ve geleneksel baskıları her iki oyunda da iyice belirtilmiştir (Uyguner, 1992, s. 493).

Derya Gülü oyunu ise, Haşim'in kapatması Meryem ile Haşim Kaptan ve Haşim'in yanaşması Sinan arasında gelişen oyunda toprağın yerini deniz alır, ama yine cinsel sorunları ele alan bir tema oyunda yer alır. Cumalı eserlerinde, toprak ve deniz arasında pek fark görmez. Derya Gülü oyununda zoraki sürdürülen bir evliliğin yükünü kadın çekmektedir. Bu durum kadının ihaneti ile sonuçlanır (And, 1973, s. 465). Derya Gülü, oyununda, kadının cinsel tatminsizliği nedeniyle ihanet eden bir kadının öç alma isteğini göstermektedir. Necati Cumalı'nın Anadolu'daki kadın sorununu cinsellik boyutuyla el aldığı bir diğer oyunu Mine'dir. Her iki oyunda da farklı çevresel koşullar altında aynı yazgıya sahip iki kadının trajedisi sunulur.

Necati Cumalı Mine isimli eserinde dengi olmayan bir erkek evli olan genç ve güzel bir kadının tutucu kasaba çevresi tarafından evliliğinin yıkımasını anlatmıştır. Burada kadının güzel olması dikkat çekerken güzel bir kadının kasaba erkekleri tarafından tacize uğraması ve kasabanın bu durumu dedikodu malzemesi yaparak evliliğin bitmesi vurgulanmıştır. Mine Toplumun kadın üzerindeki baskısını, kadının toplumda özgürce yaşayamayışını ve çevresinin kadını dişiliğinden dolayı sömürmek istemesini anlatmaktadır. Mine, Batı Anadolu dolaylarında küçük bir istasyon kasabasında geçer. Cumalı bu oyunu aracılığıyla Mine'nin özelinde toplumsal bir genelleme yapmaktadır.

Necati Cumalı romanlarında, kötü kadın tiplemesi Anası Kızından Maya isimli öyküde, öykünün akışına ters bir durumda anlatııı. Bu anlatım öykünün adını açıklamaktadır. Bir kasabada yaşanan olayda anne ile kızının öyküsü Cemal isimli bir gencin aşkıyla anlatılmaktadır. Cemal isimli gencin aşık olduğu kişi ise kadının kızı değil, kızın annesidir. Olay akışının çok farklı işlendiği bir diğer öykü ise Helvacı Güzeli' dir. Burada karmaşık aile içi ilişkiler cinsellik öğesi ile farklı şekillerde işlenmiştir. Her iki öyküde Anadolu kasaba hayatında yaşanan çarpık ahlak dışı ilişkilere dikkat çekilmiştir. Aynı çarpık ilişki durumu Uzun Bir Gece hikâyesinde de görülmektedir. 
Tütün Zamanı romanına bakıldığında ana karakter olan, Zeliş'in kadın olarak en önemli özelliklerinin, çalışkan ve çevik olmasıdır. Bu çalışkanlığının yanında oldukça güzel olan Zeliş, erkekler için ideal bir eş olarak anlatılmaktadır. "On dönümlük bir tarlanın tütününü kendi başına hak edecek kadar usta" olarak çizilen Zeliş, bu özellikleri nedeniyle babasının gözünde "erkek evlat" iletileri ile tanımlanmaktadır. Bu durum Zeliş'in babasının gözündeki yerini anlatmaktadır. Romanda dikkat çeken nokta tüm karakterlerin adı olmasına rağmen Zeliş'in anne karakterinin adının olmamasıdır. Bu dururum anne karakterini pasifliğini ve ezilmişliğini yansıtmaktadır. Zeliş'in ailesi, doğudan İzmir, Urla'ya göç etmiş bir ailedir. Bu bağlamda kadınlar çalışmakta erkekler kahvede vakit geçirmektedir. Geleneksel yapıda olan bu ailede kadınlar susarken erkekler egemendir. Zeliş'in babası Recep çalışmak yerine kızını zengin ağalardan birine vermiştir. Kızına maddi değer biçmekte kızını mal ya da para için kullanmaktadır. Zeliş romanında, kadına biçilen rol "iyi bir eş" ve "çocuk yapma" olarak belrilenmiştir. Kadının hiçbir söz hakkı yoktur. Geleneksel roller içinde kadın önce babasına sonra da kocasına itaat etmekle yükümlüdür. Kadınlar sadece kendi statülerindeki kadınlarla konuşabilmektedir. Bu konuşmalar dedikodu niteliğindedir.

Necati Cumall, eserlerinde sadece ezilen ve sömürülen kadın tiplemeleri işlememiştir. Aynı zamanda fettan kadın tiplemelerine de yer vermiştir. Bu fettan kadın tiplemesi, oldukça becerikli ve kurnazca bir şekilde olaylara yön vermektedir. Bazen bu kadın tiplemesi iki sevgiliyi mutlu sonla birleştirirken bazen de ayırabilmektedir.

Sonuç olarak, Necati Cumalı, eserlerinde köy yaşamını, gerçeklikle örtüştürerek; su sorunu, ağa baskısı, toprak sorunu, kan davası gibi Anadolu'ya ait geleneksel kültür örüntüsü içinde anlatmaktadır. Bu örüntülerin içine kadın- erkek ilişkileri, ataerkillik çerçevesinde işlenmiştir. Bu bağlamda kadın betimlemeleri kadının hem emek hem de cinsel açıdan sömürülmesi olarak gösterilmektedir. Genç kızların en çok başlık parasını verenle evlendirilmesi, bu parayı veren ailelerin aldıkları kadına köle muamelesi yapması, kocası ölen kadının kocasının erkek kardeşi ile evlendirilmesi gibi konular Anadolu'da kadının değersizleştirilmesine dikkat çekmektedir. Bunun yanı sıra Cumalı eserlerinde bu kadar değersizleştirilen kadınların, duygularına ve cinsellik gibi dürtülerine vurgu yaparak kadınların erkekler gibi toplumda eşit bir yeri olduğunu arka planda göstermeye çalışmaktadır. Necati Cumalı eserlerinde Anadolu'da kadınların duygularını yaşayamadığını ve cinsellik 
gibi en doğal isteklerini bile içlerine gömmek zorunda olduklarını anlatmaktadır.

\section{NECATi CUMALI ESERLERINDE KADIN BETIMLEMELERI: DILA HANIM ÖRNEĞi}

Necati Cumalı'nın 1978 yılında yazdığı Dila Hanım, kitabında on bir hikâye yer almaktadır. Kitabın ilk hikâyesinin baş kahramanı Dila Hanım, eşinin öldürülmesi üzerine onun intikamını almak isteyen oldukça cesur bir Arnavut kadınıdır. Hikaye 20. yüzyılın başlarında Balkan coğrafyasında, Yunanistan, Makedonya, Arnavutluk ve Kosova gibi dört ayrı ülke ile sınır ortak bir bölgede geçmektedir.

Hikaye, Dila Hanımın eşi Arnavut beyin girdiği bir çatışmada ölmesi ile başlamaktadır. Arnavut Beyin adamları cenazeleri ile çiftliğe dönerler. Hikâyenin geçtiği yer Makedonya, Yunanistan ve Arnavutluk sınırlarında kalan bir coğrafyadır. Hikâyede, o dönem yaşayan toplulukların geleneksel kültürüne dair önemli bilgiler verilmektedir. Beyler ve çalışanları arasındaki ilişki ayrıntılarıyla anlatılmaktadır. Ayrıca bey olmak için bir toprak parçası ve hayvan sahibi olmak gerektiği de vurgulanmaktadır. Kocasının ölmesi ile çok küçük yaşta (14) Arnavut Bey ile evlenen Dila Hanım, Arnavut Bey'in öldürülmesi ile genç yaşta (22) dul kalmıştır. Arnavu† Bey'den çocuğu olmayan Dila Hanım, bu ölüm ile kendisini büyük bir intikam ateşi içinde bulmuştur. Kocasının intikamını almak için yanıp kavrulmaktadır.

Dila Hanımın kendisi de bir bey kızıdır. Eşi Arnavut Bey ile evlenirken, 600 koyun çeyiz getirmiştir. Dila Hanımın eşi Arnavut Bey, bir arazi kavgasında kimin öldürdüğü belli olmayan bir şekilde öldürülmüştür. Hikâye Arnavut Beyin ölüsünün çiftliğe getirilmesinin betimlenmesi ile başlamaktadır. Bütün hikâye bu yapı üzerinden şekillenmektedir. Olumsuz bir olayla başlayan hikâye, imkânsız bir aşk hikâyesine dönüşmektedir. $\bigcirc$ dönemin geleneklerine göre, bir kişi öldürüldüğünde insanlar karakola gitmek yerine kendi intikamlarını kendileri almaktadır. Arnavut Beyin intikamını almak Dila Hanıma kalmışıı. Hikayede, Dila Hanım, intikam peşinde koşarken kocasını öldüren Rıza Beye âşık olmuştur. Bu aşkın anlatımı Dila Hanımın kendi içinde yaşadığı, duygular ile verilmiştir. Dila Hanım, kin ve aşk duyguları arasında gidip gelmektedir. Bu durum Dila Hanımı zorlarken, çevre baskısı, o dönemin Goriçka bölgesinin kültürel yapısında olan kan davası Dila Hanımı derin bir ruhsal gerilimin içine sokmuştur. Rıza beye olan aşkı, alması gereken kan davasının yarattığı ruhsal 


\section{arts}

gerilim ile Dila Hanımın bir kadın olarak karakteristik yapısı onu intihara sürüklemiştir.

Kadın olarak Dila Hanım karakterine bakıldığında, aslında geleneksel bir kadın modeli çizmektedir. Bu durumu hem küçük yaşta yaptığı evlilikten hem de evlenirken getirdiği çeyizden anlaşılmaktadır. Ayrıca o civarın Arnavut kızlarının yetiştirilme tarzına göre büyütülen Dila Hanım, Ata binmektedir ve silah kullanmaktadır. Evliliğini de kendi ailesinin seçimi ve isteği üzerine yapmıştır. Bir bey kızı olduğu için kendisinden yaşça büyük olmasına rağmen yine bir bey olan Arnavut beyle evlenmiştir. Dila hanım, Arnavut kadın geleneklerine göre yetişmiştir. Dila Hanım, kırlık yerlerde sürüler arasında yetişen çoğu Arnavut kızları gibi iyi ata biner, iyi tabanca kullanırdı. Kocası öldükten sonra biniciliği ve atıcılığı ilerletmiş, işlere sahip çıkmak ona düşmüştü. (Cumall, 1978, s. 46). O yıllarda, o civarın geleneklerine göre, insanlar o civarda bir yakınları öldürüldüğ̈̈nde yakınlarının intikamını kendileri kan dökerek almaktadır. Dila Hanım, kocası öldürüldüğü için aileden gelen asalet ile davranarak önce kocasını öldüreni bulana sürülerinin yarıını teklif etmiştir. Bakmıştır ki etrafındakiler bunu başaracak güçte değil kendisi kocasının katilinin peşine düşmüştür.

Bir kadın olarak Dila Hanımın en karakteristik özelliği cesur olmasıdır. Bu durum Arnavut gelenekleri ile büyütülmesine bağlanmaktadır. Bir Arnavut kızı olarak kırsalda büyümesi, ata binmesi ve silah kullanması tüm Arnavut kızlarının ortak özelliği olarak verilmektedir. Kocası öldürüldükten sonra Dila Hanım, hem atıcılığını hem de biniciliğini geliştirmiştir. Kocası öldükten sonra erkek kıyafetleri giyerek dolaşmaya başlamıştır. Kahyasının Rıza Beyi, öldüremeyeceğini anlayınca kendisi Rıza Beyi öldürmek için peşine düşmüştür. Bu nedenle Rıza Beyi her yerde aramaya başlamıştır. Bir handa karşılaştığı Rıza Beye aşık olmuştur. Kocasının katiline aşık olmanın verdiği utançla Dila Hanım, intihar etmiştir. Bu durum Dila Hanıma karakter olarak; çok güçlü, cesur, gururlu ve onurlu bir kadın imajı çizmektedir.

Necati Cumalı, Dila Hanım hikâye kitabında, ailesinden dinlediği ve Goriçka civarında yaşanan olayları hikâyeleştirmiştir. Bu bağlamda o dönemin yaşanmışıklarına da ışık tutan Cumalı, dinlediği hikâyeleri hayal gücü ile birleştirmiştir. Tüm Necati Cumalı eserlerinde olduğu gibi Dila Hanım, hikâyesinde de kullanılan dil günlük hayatın dili, alışımış, bilinen anlam ve çağrışımların yüklendiği kelimelerden ve sıradan söz dizimi kalıplarından oluşur (Özkan, 2015, s. 65). Cumalı'nın en dikkat 
çeken tarafı dili kullanırken uyguladığı sade üsluptur. Bu üslup Cumalı'nın eserlerini güçlü kılmaktadır. Cumalı dilde kullandığı güçlü üslupla geniş kitlelere ulaşmaktadır. Eserlerinde sıradan insanın, günlük hayatının yaşanışını kullandığı dilin gücü ile etkili kılmıştır. Bu durum Cumalı'nın sanatsal gücünü ve kendine has üslubunu göstermektedir. Kendine has özgün bir anlatım gücü ile kitlelere ulaşan Cumalı bu şekilde yeni kurulan genç Cumhuriyetin önemli bir yazarı olarak hareket etmiştir.

\section{SONUÇ}

Necati Cumalı, eserlerinde Anadolu insanının geleneksel kültür altında yaşayış biçimlerine ve bu kültürden kaynaklı davranışlarına yer vermiştir. Yapıtları o dönemin Anadolu insanına ve kültürüne ışık tutmaktadır. Bu bağlamda Cumalı'nın eserlerine bakıldığında, kasaba insanına ait yaşam biçimleri ve kırsal kesim ilişkileri göze çarpmaktadır. Bu ilişkiler içinde, toprak kavgası, kan davası, kasaba ve köy yaşamında bu çatışmalar içinde kadınların rol ve statüleri anlatılmaktadır.

Aslında Cumalı, eserlerinde o dönemin toplumsal sorunlarına ışık tutmaktadır. Bu ışık tutmada en fazla kadınların yaşadığı sıkıntılara dikkat çekmektedir. Bu toplumsal sorunları ele alırken aşk, kıskançlık, nefret gibi insani özellikleri ön plana çıkarmıştır. Pek çok eserinde kırsal yaşamda karşılaşılan toplumsal baskılar yitirilen insani özellikler ile ifade edilmiştir. Özellikle aşk ve sevgiye dair anlatımlarda bu durum görülmektedir. Özellikle toprağa bağlı yaşam süren Anadolu insanının üzerindeki töre baskısı aşk ve sevgi duygusu ile anlatılmıştır. Bu töre baskısının insanların hayatını nasıl esaret altına aldığına dikkat çekilmektedir. Bu töre esaret altında kadınlar genellikle birbirinden ayrımayan davranışlar sergilerler. Örneğin boyun eğme gibi. Kadınlar ister kentte, ister kasabada isterse köyde yaşasın toplumsal baskılara boyun eğen ve hep geleneksel kalıplara sıkışan, bağımlı ve her açıdan sömürülen çileli kişiler olarak anlatılmaktadır.

Necati Cumalı'nın Dila Hanım hikâyesinde birinci ağızdan anlatım vardır. Cumalı'nın sade ve etkileyici güçlü üslubu burada da kendini göstermektedir. Aynı şekilde Dila Hanım öyküsündeki Dila Hanım karakteri bazı yönlerden Anadolu kadınından farklı olsa da kaderine boyun eğmesi ve törelere boyun eğmesi açısından benzerlik göstermektedir. Hikaye'nin Balkan coğrafyasında geçmesi bir 
kadının kaderini değiştirememiştir. Yine bir kadın daha aşkı yerine kaderine boyun eğmeyi tercih etmiştir. Burada anlatılan kadın karakteri Anadolu ne kadar güçlü, onurlu ve savaşçı olursa olsun geleneklere baş kaldıramamıştır.

\section{KAYNAKÇA}

And, M. (1973). 50 Yllın Türk Tiyatrosu. İstanbul: İş Bankası.

Cumalı, N. (1978). Dila Hanım - Makedonya 1900. İstanbul: E.

Cumalı, N. (1995). Viran Dağlar Makedonya 1900. Ankara: Cumhuriyet Kitapları.

Demir, Y. (1995). Anlatılar Tipolojisi. İstanbul: Akçağ.

Özkan, M. (2015). Edebiyatta Dil Kullanımı. İstanbul Üniversitesi Türk Dili ve Edebiyatı Dergisi, 52, 65-76.

Taş, S. (2001). Necati Cumalı ve Oyunları. Ankara: Kültür Bakanlığı Kültür Eserleri.

Uyguner, M. (1992). Cumalı'nın Tiyatro Yapıtları. Türk Dili, 228, 491-493. 